\title{
Successful management of a patient with sudden loss of vision and eclampsia complicated by posterior reversible encephalopathy syndrome
}

\section{Babita Vaswani*, Sriram Gopal, Meena Satia}

Department of Obstetrics and Gynaecology, Dr. D. Y. Patil, Hospital and Research Centre, Nerul, Navi Mumbai, Maharashtra, India

Received: 26 August 2019

Accepted: 30 September 2019

\author{
*Correspondence: \\ Dr. Babita Vaswani, \\ E-mail: vaswani.babita@gmail.com
}

Copyright: () the author(s), publisher and licensee Medip Academy. This is an open-access article distributed under the terms of the Creative Commons Attribution Non-Commercial License, which permits unrestricted non-commercial use, distribution, and reproduction in any medium, provided the original work is properly cited.

\begin{abstract}
Reversible visual disturbances in patients with eclampsia may be due to either retinal detachment or retinal arteriolar vasospasm or thrombosis of the central retinal arteries or PRES (posterior reversible encephalopathy syndrome). Although retinal arteriolar vasospasm is the most common mechanism of visual disturbance, cortical blindness may occur in $1 \%$ to $15 \%$ of patients with eclampsia. Reporting herewith a case of reversible cortical blindness in the setting of severe preeclampsia complicated with eclampsia.
\end{abstract}

Keywords: Cortical blindness, Eclampsia, Hypertension, Posterior reversible encephalopathy syndrome, Preeclampsia, Reversible

\section{INTRODUCTION}

Pre-eclampsia is a syndrome complex peculiar to pregnancy and parturition and is associated with hypertension and proteinuria. It complicates $1-5 \%$ of all pregnancies and is one of the leading causes of maternal morbidity and mortality. ${ }^{1}$ Its etiology is unknown but abnormal trophoblastic invasion of spiral arteries, endothelial cell activation and exaggerated inflammatory response are mainly involved in the pathogenesis of preeclampsia. Increased vascular permeability is seen due to endothelial cell activation and presents as edema and hypoproteinemia. In the brain due to acute and severe hypertension there is cerebrovascular overregulation leading to vasospasm, ischemia, cytotoxic edema and eventually tissue infarction with resultant convulsions. ${ }^{2}$ Preeclampsia/eclampsia can have various ocular manifestations. Blurred vision is the most common visual symptom. Sudden and complete blindness is a rare presentation of preeclampsia and is manifested in $1-3 \%$ of patients with severe preeclampsia/eclampsia. ${ }^{3}$ It is defined as blindness occurring in association with normal fundoscopy and pupillary function. ${ }^{4}$ It may occasionally be the first clinical symptom preceding seizures by 4-7 hours as was seen in our patient. PRES (posterior reversible encephalopathy syndrome) is a rare neurological syndrome first described in 1996. Its clinical manifestation varies and is nonspecific.

Clinical presentation of patients with PRES syndrome varies from headaches, consciousness disorders, seizures, vomiting, mental status changes and visual abnormalities. ${ }^{5}$ Pre-eclampsia or eclampsia is the most common cause of PRES. ${ }^{6}$ Most PRES cases associated with pre-eclampsia/eclampsia are postpartum and intrapartum, rather than antepartum. ${ }^{7}$ Visual abnormalities in PRES commonly include blurred vision hemianopia. ${ }^{5}$ Reversible cortical blindness is a very rare symptom in these patients. 


\section{CASE REPORT}

A 19 years old primigravida with 33 weeks of gestation was admitted at a tertiary care center with severe headache followed by convulsion at home with antepartum hemorrhage. This was associated with complete loss of vision in both eyes just prior to convulsions. History from relatives revealed that she was diagnosed as case of severe pe-eclampsia since 1 month and was taking antihypertensive tablets since then. Patient was advised admission for thorough evaluation for pre-eclampsia but refused. Patient was referred to a tertiary care center from a peripheral hospital where she was given a loading dose of injection $\mathrm{MgSO}_{4}$. On admission she was conscious and well oriented, her Pulse was $100 / \mathrm{min}$ and her blood pressure were 130/100 $\mathrm{mmHg}$. She had no pallor but had pedal edema. No abnormality was detected in her respiratory and cardiovascular systems. On per abdominal examination uterus corresponding to 32 weeks with a single fetus, longitudinal lie with cephalic presentation with FHS of $136 / \mathrm{min}$. She had slight uterine tenderness so suspicion of abruptio placenta was made. In view of sudden loss of vision, an urgent ophthalmology reference was taken and fundoscopy was done which showed no evidence of retinal detachment, normal pupillary reflexes and no papilledema indicating cortical blindness. MRI brain was advised to rule out PRES syndrome or intracranial bleed but patients' relatives refused. A clinical impression of PRES was made and she was immediately started on Inj. Mannitol and $\mathrm{MgSO}_{4}$ infusion at the rate of $1 \mathrm{~g} /$ hour. On investigations PIH profile was within normal limits and coagulation profile too was normal. USG was done which revealed SLIUG of 31 weeks and EFW of $1.5 \mathrm{kgs}$ and a retroplacental clot of approximately $4 \times 5 \mathrm{cms}$. In view of the above findings and clinical suspicion of abruptio placenta, an Emergency LSCS was done. Intraoperative findings: a couvelaire uterus was seen and a female child of $1.2 \mathrm{~kg}$ was born and shifted to NICU and a retroplacental clot of 300 gms was removed. Postoperatively $\mathrm{MgSo}_{4}$ infusion and antihypertensives were continued. Her vision started to return from postoperative day 2 onwards. Initially she had only blurring of vision but her vision slowly improved and she had full recovery by sixth postoperative day and was discharged on 8th postoperative day after complete return of her vision and an ophthalmology fitness for discharge.

\section{DISCUSSION}

The exact mechanism of cortical blindness in preeclampsia/eclampsia is unclear. It may result from cerebral vasospasm and ischemic injury or it may arise from vasogenic edema due to increased capillary permeability in the occipital region of the cerebral cortex. Recently, single-photon emission tomography studies supported the finding that elevated capillary permeability and vasogenic edema are involved in cases of cortical blindness. Cortical lesions are usually bilateral and is often in the posterior cortical areas. ${ }^{3,4,8}$ The pathophysiological mechanism of PRES caused by preeclampsia is still not clear. One hypothesis is that high blood pressure causes cerebrovascular autoregulation failure, resulting in hyper perfusion. Another is that hypoperfusion is caused by vasospasm or vasoconstriction. Vasogenic edema in brain tissue occurs in both hypotheses. ${ }^{9}$ Consequently, there is endothelial damage, at least in part, at the blood-brain barrier. ${ }^{10}$ If vasogenic edema occurs in the visual cortex of the patient, it can cause cortical blindness. As PRES improved and resolved after delivery of the baby and placenta, as in our case, it is suggested that the culprit may be in the placenta. ${ }^{6,11}$ The endothelial damage noted in the placenta may be paralleled in the endothelial damage at the blood-brain barrier with a possible common aetiology. ${ }^{12,13}$ It is imperative that clinicians, including obstetricians, ophthalmologists and neurologists are familiar with variable features and factors of PRES and its association with blindness. A fundoscopy examination is essential to diagnose a patient with pre-eclampsia who complains of ophthalmic symptoms. If cerebral edema is suspected, an MRI must also be performed. In PRES, the MRI image shows symmetrical or bilateral vasogenic edema in the parietal and occipital lobe. Vasogenic edema is also commonly found in the frontal lobe, temporal lobe and cerebellar hemisphere. ${ }^{5}$ In the brain edema area, an MRI image shows hypointense or isointense signals in T1WI and hyperintense signals in T2WI and FLAIR sequence. ${ }^{14,15}$ The key to treat pre-eclampsia and PRES include control of blood pressure, prevention of seizures, and induction of labour. ${ }^{16}$ Antihypertensive treatment should be given when the patient's systolic pressure is consistently higher than $160 \mathrm{mmHg}$ or diastolic blood pressure is 105-110 $\mathrm{mmHg}$ or above. Common antihypertensive drugs include labetalol, hydralazine and short-acting oral nifedipine. The preferred medicine to prevent seizures is magnesium sulphate to relieve vascular spasm. Fortunately, blindness due to occipital lesions is reversible and the lost vision is usually regained within 4 hours to 8 days. $3,4,17,18$

\section{CONCLUSION}

Because 90 percent of women presenting with severe preeclampsia/ eclampsia have a headache and close to one half of them have some type of visual disturbance, physicians providing obstetric care should be alert for these symptoms as an unusual presentation of this disease and must be vigilant. Fundoscopy and MRI brain are mandatory and timely intervention is the key to success.

Funding: No funding sources

Conflict of interest: None declared

Ethical approval: Not required

\section{REFERENCES}

1. Cunningham FG, Leveno KL. Hypertensive Disorders. In: Steven L. Bloom, Catherine Y. Spong, 
Jodi S. Dashe, Barbara L. Hoffman, Brian M. Casey, Jeanne S. Sheffield, editors. Williams Obstetrics. $24^{\text {th }}$ ed. USA: McGraw-Hill Education; 2014:728.

2. Bansal V, Damania KR. Hypertensive disorders in pregnancy. In: Amarnath B, Arulkumaran S, Damania KR, Daftary SN, editors. Arias' Practical Guide to high risk pregnancy and delivery. $4^{\text {th }}$ ed. India: Elsevier; 2015:201-205.

3. Jyotsana, Sharma AK, Bhatt S. Reversible blindness in severe preeclampsia. JK Sci. 2004;6:43-5.

4. McCormick AS, Wood A, Wee MY. Visual disturbances and seizures associated with pregnancy: a diagnostic dilemma and the role of radiological techniques as an aid to diagnosis. Int $\mathrm{J}$ Obstet Anesth. 1999;8:184-8.

5. Hinchey J, Chaves C, Appignani B, Breen J, Pao L, Wang A, et al. A reversible posterior leukoencephalopathy syndrome. New Eng J Med. 1996;334(8):494-500.

6. Liman TG, Bohner G, Heuschmann PU, Endres M, Siebert E. The clinical and radiological spectrum of posterior reversible encephalopathy syndrome: The retrospective Berlin PRES study. J Neurol. 2012;259(1):155-64.

7. Hegde HV, Patil PB, Rameshkumar R, Sunita TH, Bhat MT, Desai RM, et al. A rare case of antepartum posterior reversible encephalopathy syndrome. Anaesth Intens Care. 2011;39(3):499-502.

8. Cunningham FG, Fernandez CO, Hernandez C. Blindness associated with preeclampsia and eclampsia. Am J Obstet Gynecol. 1995;172:1291-8.

9. Bartynski WS. Posterior reversible encephalopathy syndrome, part 2: Controversies surrounding pathophysiology of vasogenic edema. AJNR Am J Neuroradiol. 2008;29(6):1043-9.

10. Pula JH, Eggenberger E. Posterior reversible encephalopathy syndrome. Curr Opin Ophthalmol. 2008;19(6):479-84.
11. Servillo G, Striano P, Striano S, Tortora F, Boccella $\mathrm{P}$, De RE, et al. Posterior reversible encephalopathy syndrome (PRES) in critically ill obstetric patients. Intens Care Med. 2003;29(12):2323-6.

12. Redman CW, Sargent IL. Latest advances in understanding preeclampsia. Sci. 2005;308(5728):1592-4.

13. Noris M, Perico N, Remuzzi G. Mechanisms of disease: Pre-eclampsia. Nat Clin Pract Nephrol. 2005;1(2):98-114.

14. Hugonnet E, Da ID, Boby H, Claise B, Petitcolin V, Lannareix $\mathrm{V}$, et al. Posterior reversible encephalopathy syndrome (PRES): Features on CT and MR imaging. Diag Intervent Imag. 2013;94:4552.

15. Doelken M, Lanz S, Rennert J, Alibek S, Richter G, Doerfler A. Differentiation of cytotoxic and vasogenic edema in a patient with reversible posterior leukoencephalopathy syndrome using diffusion-weighted MRI. Diag Intervent Radiol. 2007;13(3):125-8.

16. Sibai B, Dekker G, Kupferminc M. Pre-eclampsia. Lancent. 2005;365(9461):785-99.

17. Tung CF, Peng YC, Chen GH. Hemolysis, elevated liver enzymes and low platelet count (HELLP) syndrome with acute cortical blindness. Chin Med J (Taipei). 2001;64:482-5.

18. Swende TZ, Abwa T. Reversible blindness in fulminating preeclampsia. Ann Afr Med. 2009;8(3):189-91.

Cite this article as: Vaswani B, Gopal S, Satia M. Successful management of a patient with sudden loss of vision and eclampsia complicated by posterior reversible encephalopathy syndrome. Int J Reprod Contracept Obstet Gynecol 2019;8:4590-2. 